\title{
Characteristics and Cluster of Lifestyle Factors in Neurological Outpatients
}

\author{
Myriam Galfo, M.Sc. ${ }^{1}$, Antonino Morocutti, M.D. ${ }^{2}$, Laura D’Addezio, M.Sc. ${ }^{1}$, \\ Francesca Melini, M.Sc. ${ }^{1}$
}

${ }^{1}$ Council for Agricultural Research and Economics (CREA), Research Center for Food and Nutrition, Via Ardeatina 546, Rome 00178, Italy.

${ }^{2}$ UOC Neurology ASL Roma 2 S. Eugenio Hospital, Piazzale Umanesimo 10, Rom 00144, Italy.

Received 12 May $2020 \bullet$ Revised 26 May 2020 • Accepted 3 June $2020 \bullet$ Published online 14 September 2020

\begin{abstract}
:
Objective: Neurological disorders are increasing, because of demographic and epidemiologic changes occurring in both developed and developing countries. This study was aimed at examining and clustering lifestyle factors in an Italian sample of neurological outpatients.

Material and Methods: A total of 153 subjects were recruited from the ambulatory Unit Operative Complex of neurology, of S. Eugenio Hospital in Rome. This study was conducted from January, 2017 to May, 2019. Body Mass Index (general obesity) and Waist Circumference (abdominal obesity) were used as outcome measures. Lifestyle behaviours were assessed via questionnaires.

Results: The percentage of overweight/obesity was $74.0 \%$ ( $77.0 \%$ in males and $70.0 \%$ in females); whereas, the percentage of subjects with abdominal obesity (67.0\%) was significantly higher in females than in males $(76.0 \%$ vs $60.0 \%$, p-value= 0.038). Also, among patients suffering from neurological diseases there was a significant prevalence of: (i) males, (ii) subjects with low education levels, iii) elderly adults (aged over 75), and iv) people having a significantly lower percentage of appropriate hours of sleep. Three clusters were identified for males and four for females, according to lifestyles. The 'unhealthy habits' cluster, dominant among males (38.4\%), was characterized by high prevalence of overweight/obese, and abdominal obese subjects; high prevalence of wine and alcoholic beverages consumers, high prevalence of inactive subjects; especially in females and high prevalence of neurological diseases among males.
\end{abstract}

Contact: Myriam Galfo, M.Sc.

Council for Agricultural Research and Economics (CREA)

Research Center for Food and Nutrition, Via Ardeatina 546, 00178 Rome, Italy.

E-mail: myriam.galfo@crea.gov.it

This is an open access article under the CC BY-NC-ND license

(http://www.jhsmr.org/index.php/jhsmr/about/editorialPolicies\#openAccessPolicy).

J Health Sci Med Res 2021;39(1):1-12 doi: $10.31584 /$ jhsmr.2020763 www.jhsmr.org 
Conclusion: The clusters were identified according to lifestyles, and the main, important findings showed a high prevalence of unhealthy lifestyle clustering was dominant among male, elderly people with neurological diseases.

Keywords: cluster, lifestyle factors, neurological diseases, overweight/obesity

\section{Introduction}

Neurological and neurodegenerative diseases encompass an array of diseases that do not only imply brain impairments, but also affect patient well-being. These imply progressive, degeneration and/or death of neurons in the Central Nervous System, which can effect body movement and brain function, and thus cause dementia. This disease, is a progressive or chronic decline of cognitive functions; such as, memory, thinking, behaviour, language, calculation, learning and emotion capacity, should never be associated with a normal aging process. Most of these diseases are associated with age, as their incidence increases in the elder., ${ }^{1,2}$

Neurological disorders are increasing, because of demographic and epidemiologic changes occurring in both developed and developing countries ${ }^{3}$. According to the last reports from the World Health Organization (WHO), over 1 billion people are currently affected by neurological disorders. ${ }^{1}$

Neurological disorders account for more than $6.0 \%$ of the global burden of diseases, with a higher preponderance of mortality and disability-adjusted life years in low and middle income countries. ${ }^{4}$ Stroke, epilepsy and dementia rank among the major causes of death and disability, and often impinge on working-aged adults. ${ }^{5}$

Estimates show an annual incidence of $7.5 \%$ and a prevalence of $30.0 \%$, for diseases affecting the nervous system that require the attention of a neurology specialist. ${ }^{6}$ Further to these figures, should be added an array of nervous system diseases that are not referred, for various reasons, to a neurologist: headaches, dementia, lower back pain (which represents the principal cause of days off at work in the western world), and others. In Italy, the prevalence of chronic pain is $27.0 \%$, according to the latest estimates ${ }^{6}$, while accurate data on neuropathic pain are not available. If we consider the same frequency ratio between chronic and neuropathic pain detected in Europe, it can be estimated that the neuropathic pain prevalence should be around $6.0 \%$ in the Italian population.

Based on the epidemiological and social importance of these diseases, a number of healthcare policies have thus been developed in Italy, such as: the Decree of 4, October, 2010 for the Distribution of financial resources, assigned to the Fund for Non-self-sufficient subjects and whose beneficiaries also include patients with these symptoms. This is in addition to the creation of a Neuromuscular Diseases Advisory Centre (Ministerial Decree on the 27, February, 2009). ${ }^{6}$

The aim of the present study was to examine characteristics and cluster of lifestyle factors in an Italian sample of neurological outpatients, in order to contribute to the identification of lifestyles that can improve health and life quality.

\section{Material and Methods}

A cross sectional study was conducted in patients attending the ambulatory Unit Operative Complex of neurology of S. Eugenio Hospital in Rome, from January, 2017 to May, 2019. From the total of 165 patients enrolled in the study, 12 were excluded due to incomplete questionnaires. Overall, 153 subjects (87 males and 66 females) were included in the analysis relative to this paper. 
Weight, height and waist circumference measurements were carried out by trained staff; according to WHO recommendations. ${ }^{7}$ Standing height was recorded to the nearest $0.1 \mathrm{~cm}$, by a non-elastic measuring tape without shoes. Weight was recorded to the nearest 50 gr, by a digital weighing scale without shoes. Waist Circumference (WC) was measured to the nearest 0.5 $\mathrm{cm}$, in triplicate by a metric tape; the average of three measurements was used. WC was taken midway, between the lowest rib and iliac crest, using a flexible tape applied directly to uncovered skin at the end of normal expiration, and was measured to the nearest millimeter. Body mass index (BMI) was calculated as the weight in kilograms divided by the square of the height in meters $\left(\mathrm{kg} / \mathrm{m}^{2}\right)$. It was then categorized according to guidelines (underweight or normal weight $\leq 24.9 \mathrm{~kg} / \mathrm{m}^{2}$, overweight $24.9-29.9 \mathrm{~kg} / \mathrm{m}^{2}$ and obese $\geq 30 \mathrm{~kg} / \mathrm{m}^{2}$ ). WC was classified to be an indicator for abdominal obesity when it exceeded 102 centimeters for men and $88 \mathrm{~cm}$ for women. These cut-points are associated with a significantly higher risk for metabolic and cardiovascular complications. Waist Circumference/Height ratio (WC/Ht) was calculated, and the subjects were classified using the cut-off of 0.5 : WC/ $\mathrm{H} t \geq 0.5$ and $W C / H t<0.5{ }^{8}$

A structured questionnaire was administered, consisting of; socio demographic and lifestyle information, details regarding nutritional status, sleep duration, smoking/ drinking habits, physical activity and comorbidities.

Informed written consent was obtained from all the study participants before the start of data collection. Data collected were kept confidential and used only for research purposes.

The descriptive analyses are presented as the means \pm standard deviations for quantitative variables, and as percentages for categorical variables. Student's t-test and Pearson chi-square test for categorical variables were conducted, to investigate the association between gender and socio-demographic and lifestyle factors and occurrence of neurological disease.

Cluster analysis was used to identify profiles of similar patients regarding lifestyle factors, including nutritional status, abdominal obesity, physical activity, wine and alcohol consumption, smoking status and sleep duration. Cluster analysis was performed separately for males and females, since some of the lifestyle variables significantly differed by gender. All categorical variables, considered in the cluster analysis, were recoded into binary variables, and a combination of different methods was used to obtain the cluster solution.

First, several hierarchical methods were used to explore the clustering structure and to determine the number of existing clusters. A two-step clustering method, which allows for the inclusion of categorical variables, was subsequently used to obtain the final solutions. A new qualitative variable (cluster membership) was created, indicating the cluster to which each patient belonged. The clusters' description was based on analysis of contingency tables between each clustering variables and cluster membership. The relationship between cluster membership along with age class, education and occurrence of neurological disease was also investigated through contingency tables and chi-square test. Statistical Package for the Social Sciences 17.0 (SPSS Inc, Chicago, llinois, the United State of America) was used for the statistical calculations, values of $p$-value $<0.05$ were considered to be significant.

\section{Results}

The characteristics of participants are presented in Table 1. The sample comprises of 153 individuals: 87 $(57.0 \%)$ males and 66 (47.0\%) females, aged between 41 and 94 . The mean age was 73 years (75 for males and 70 for females). A total of $45.0 \%$ declared a level of education from upper secondary to university degree, $49.4 \%$ of them were males ( $p$-value $=0.217$ ). 
The average BMl was 27.5 , with $26.0 \%$ of normal obese rate rised to $77.0 \%$ in males and dropped to weight and $74.0 \%$ of overweight or obese. Overweight/ $70.0 \%$ in females ( $p$-value $=0.30$ ).

Table 1 Baseline characteristics, lifestyle and disease for total sample, by gender

\begin{tabular}{|c|c|c|c|c|}
\hline Characteristics & $\begin{array}{l}\text { Total sample } \\
n=153\end{array}$ & $\begin{array}{l}\text { Males } \\
\mathrm{n}=87(56.6 \%)\end{array}$ & $\begin{array}{l}\text { Females } \\
n=66(43.4 \%)\end{array}$ & p-value \\
\hline Age, years \pm S.D. & $73.1 \pm 11.5$ & $75.2 \pm 10.4$ & $70.5 \pm 12.4$ & $0.014^{a}$ \\
\hline Weight, kg \pm S.D. & $74.9 \pm 13.5$ & $80.2 \pm 11.7$ & $67.9 \pm 12.6$ & $\leq 0.000^{\mathrm{a}}$ \\
\hline Height, $\mathrm{cm} \pm$ S.D. & $165.1 \pm 9.8$ & $170.5 \pm 7.7$ & $157.9 \pm 7.4$ & $\leq 0.000^{\mathrm{a}}$ \\
\hline BMl & $27.5 \pm 4.3$ & $27.6 \pm 3.7$ & $27.3 \pm 4.9$ & $0.593^{\mathrm{a}}$ \\
\hline Waist circumference/height ratio $(\mathrm{WC} / \mathrm{Ht}) \pm$ S.D. & $0.6 \pm 0.08$ & $0.6 \pm 0.1$ & $0.6 \pm 0.1$ & $0.355^{\mathrm{a}}$ \\
\hline \multicolumn{5}{|l|}{ Age class } \\
\hline$<65$ & $21.6(33)$ & $16.1(14)$ & $28.8(19)$ & \multirow[t]{3}{*}{$0.094^{b}$} \\
\hline$\geq 65-75$ & $25.5(39)$ & $24.1(21)$ & $27.3(18)$ & \\
\hline$>75$ & $52.9(81)$ & $59.8(52)$ & $43.9(29)$ & \\
\hline \multicolumn{5}{|l|}{ Education } \\
\hline No formal education/primary/ower secondary & $54.9(84)$ & $50.6(44)$ & $60.6(40)$ & \multirow[t]{2}{*}{$0.217^{b}$} \\
\hline Upper secondary/university degree & $45.1(69)$ & $49.4(43)$ & $39.4(26)$ & \\
\hline \multicolumn{5}{|l|}{ Nutritional status } \\
\hline Normal weight & $26.1(40)$ & $23.0(20)$ & $30.3(20)$ & \multirow[t]{2}{*}{$0.308^{b}$} \\
\hline Overweight or obese & $73.9(113)$ & $77.0(67)$ & $69.7(46)$ & \\
\hline \multicolumn{5}{|l|}{ Abdominal obesity } \\
\hline Yes & $66.7(102)$ & $59.8(52)$ & $75.8(50)$ & \multirow[t]{2}{*}{$0.038^{\mathrm{b}}$} \\
\hline No & $33.3(51)$ & $40.2(35)$ & $24.2(16)$ & \\
\hline \multicolumn{5}{|l|}{ Smoking } \\
\hline Current smoker & $15.7(24)$ & $13.8(12)$ & $18.2(12)$ & \multirow[t]{2}{*}{$0.460^{b}$} \\
\hline No smoker/former smoker & $84.3(129)$ & $86.2(75)$ & $81.8(54)$ & \\
\hline \multicolumn{5}{|l|}{ Alcohol consumption } \\
\hline Yes & $32.2(49)$ & $38.4(33)$ & $24.2(16)$ & \multirow[t]{2}{*}{$0.065^{b}$} \\
\hline No & $67.8(103)$ & $61.6(53)$ & $75.8(50)$ & \\
\hline \multicolumn{5}{|l|}{ Wine consumption } \\
\hline Everyday & $20.4(31)$ & $26.7(23)$ & $12.1(8)$ & \multirow[t]{2}{*}{$0.027^{b}$} \\
\hline Not every day/never & 79.6 (121) & $73.3(63)$ & $87.9(58)$ & \\
\hline \multicolumn{5}{|l|}{ Physical activity } \\
\hline Yes & $34.0(52)$ & $37.9(33)$ & $28.8(19)$ & \multirow[t]{2}{*}{$0.237^{b}$} \\
\hline No & $66.0(101)$ & $62.1(54)$ & $71.2(47)$ & \\
\hline \multicolumn{5}{|l|}{ Sleep duration (hours) } \\
\hline$<6$ & $29.4(45)$ & $29.9(26)$ & $28.8(19)$ & \multirow[t]{2}{*}{$0.883^{b}$} \\
\hline$\geq 6$ & $70.6(108)$ & $70.1(61)$ & $71.2(47)$ & \\
\hline \multicolumn{5}{|l|}{ Neurological disease } \\
\hline Yes & $52.6(80)$ & $57.0(49)$ & $47.0(31)$ & \multirow[t]{2}{*}{$0.221^{b}$} \\
\hline No & $47.4(72)$ & $43.0(37)$ & $53.0(35)$ & \\
\hline \multicolumn{5}{|l|}{ Dementia } \\
\hline Yes & $9.9(15)$ & $11.6(10)$ & $7.6(5)$ & \multirow[t]{2}{*}{$0.406^{b}$} \\
\hline No & $90.1(137)$ & $88.4(76)$ & $92.4(61)$ & \\
\hline
\end{tabular}


Table 1 (continued)

\begin{tabular}{|c|c|c|c|c|}
\hline Characteristics & $\begin{array}{l}\text { Total sample } \\
n=153\end{array}$ & $\begin{array}{l}\text { Males } \\
\mathrm{n}=87(56.6 \%)\end{array}$ & $\begin{array}{l}\text { Females } \\
n=66(43.4 \%)\end{array}$ & $\mathrm{p}$-value \\
\hline \multicolumn{5}{|l|}{ Stroke } \\
\hline Yes & $6.6(10)$ & $8.1(7)$ & $4.5(3)$ & $0.376^{b}$ \\
\hline No & 93.4 (142) & $91.9(79)$ & $95.5(63)$ & \\
\hline \multicolumn{5}{|l|}{ Parkinson } \\
\hline Yes & $19.7(30)$ & $24.4(21)$ & $13.6(9)$ & $0.098^{b}$ \\
\hline No & 80.3 (122) & $75.6(65)$ & $86.4(57)$ & \\
\hline \multicolumn{5}{|l|}{ Diabete } \\
\hline Yes & $14.5(22)$ & $18.6(16)$ & $9.1(6)$ & $0.098^{b}$ \\
\hline No & 85.5 (130) & $81.4(70)$ & $90.9(60)$ & \\
\hline \multicolumn{5}{|l|}{ Hypertension } \\
\hline Yes & $44.1(67)$ & 40.7 (35) & 48.5 (32) & $0.338^{b}$ \\
\hline No & 55.9 (85) & $59.3(51)$ & 51.5 (34) & \\
\hline
\end{tabular}

${ }^{a}$ Comparison between males and females, based on t-test

${ }^{\mathrm{b}}$ Comparison between males and females, based on chi-square test

S.D.=standard deviation, $\mathrm{kg}=$ kilograms, $\mathrm{cm}=$ centimeters, $\mathrm{BMl}=$ body mass index

There was a significantly, higher percentage of patients with abdominal obesity $(67.0 \%$ in total) among females $(76.0 \%)$ than among males $(60.0 \%)$, p-value= 0.038. With regard to lifestyle and health factors, examined subjects revealed that: in males there was a higher prevalence of habitual consumers of wine $(26.7 \%$ vs. $12.1, p-$ value $=0.027)$ and other alcoholic beverages $(38.4 \%$ vs. $24.2 \%, p$-value $=0.065)$ with respect to females, and also a higher percentage of people who practiced physical activity (37.9\% vs. $28.8 \%$, $p$-value $=0.237)$. The rate of neurological patients was higher for males than females $(57.0 \%$ vs. $47.0 \%$, p-value= 0.221), in particular they comprised of subjects suffering from dementia $(11.6 \%$ vs $7.6 \%$, p-value=0.406), stroke (8.1\% vs. $4.5 \%$, p-value $=0.376)$ and Parkinson's disease (24.4\% vs. $13.6 \%, p$-value $=0.098)$. In males a higher percentage of patients with diabetes was observed (18.6\% vs. 9.1\%, p-value=0.098). Among females there was a higher prevalence of smokers $(18.2 \%$ vs. $13.2 \%$, $p$-value $=0.460)$ and hypertensive patients $(48.5 \%$ vs. $40.7 \%$, p-value $=0.338$ ).
An adequate sleep time concerns $71.0 \%$ of the sample, with no difference between genders.

\section{Demographic and lifestyle factors in relation} to neurological disease (Table 2)

Among patients suffering from neurological disease only, or even in the presence of one more nonneurological disease, there was a higher prevalence of subjects with a low educational level than those who do not suffer from any neurological disease $(62.5 \%$ vs. $37.5 \%$, p-value=0.039).

Among people with dementia, the percentage of people with a lower education level was higher than among those without dementia ( $80.0 \%$ vs. $51.8 \%$, p-value=0.037), also the percentage of over 75-year-old people was higher $(86.7 \%$ vs. $49.6 \%$, p-value=0.024). Among stroke patients, a higher percentage of people who regularly practice physical activity was observed $(70.0 \%$ vs. $31.7 \%$, $p$-value $=0.014)$. Among neurological patients, particularly those with Parkinson's disease, the prevalence of appropriate hours of sleep was lower ( $\geq 6$ sleep hours, 


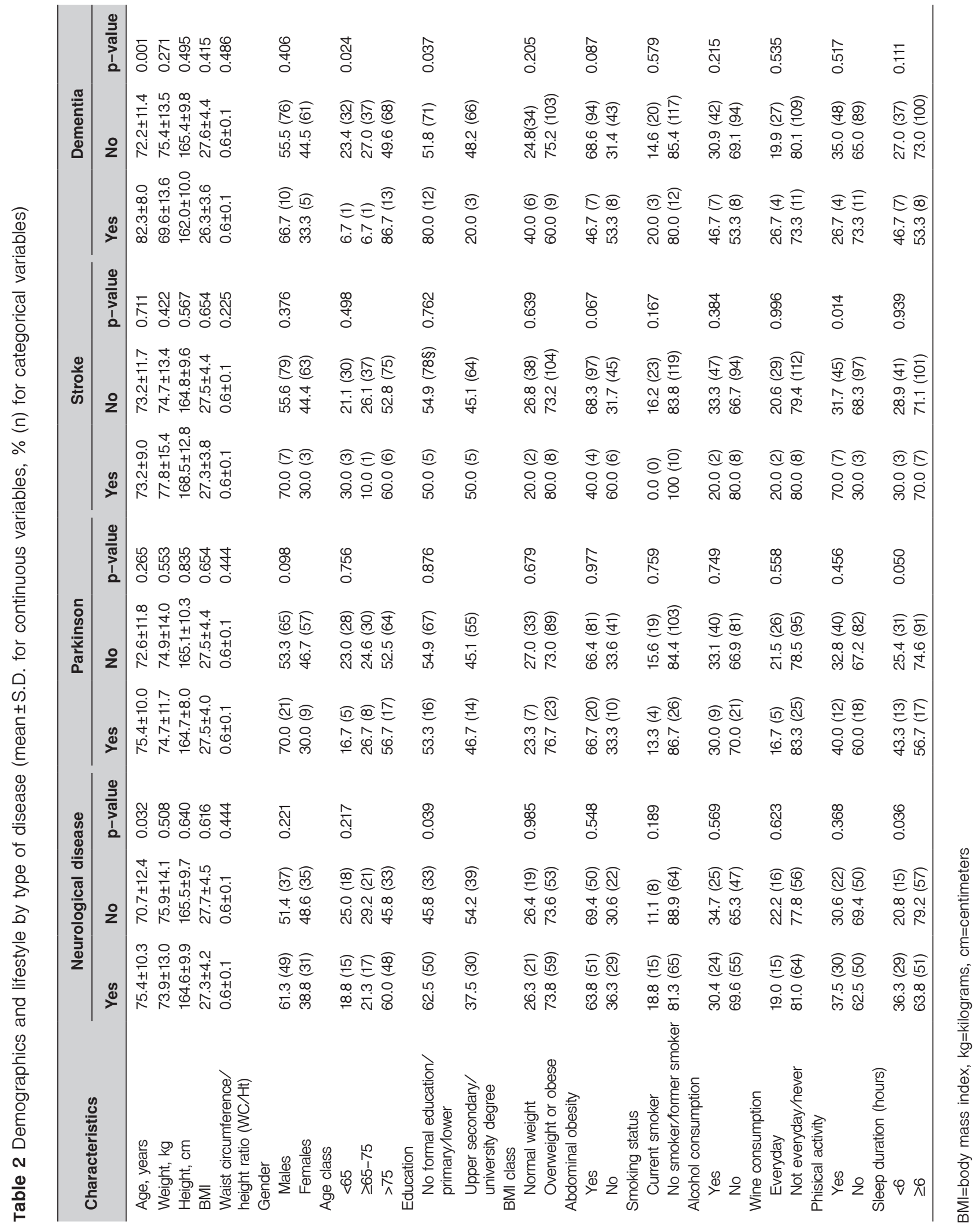


$63.8 \%$ in neurological patients vs. $79.2 \%$ in non-neurological patients, $p$-value $=0.036$; $\geq 6$ sleep hours, $56.7 \%$ in Parkinson patients vs. $74.6 \%$ in non-Parkinson patients, $\mathrm{p}-$ value $=0.05$ ).

Description of clusters of lifestyle factors, and their associations with age class, education and neurological disease.

Figure 1 and Figure 2 show the clusters of lifestyle factors obtained for males and females, respectively. In these figures, each estimated cluster is named reporting its dimension. In each cluster the prevalence of clustering variables, as well as prevalence of the three evaluation variables (for example; age class, education and presence of neurological disease) is reported as percentage. Three clusters were identified for males:

Cluster $1=$ Unhealthy habits, consisting of 33 subjects $(38.4 \%)$

Cluster 2=Active, consisting of 30 subjects

Cluster $3=$ Sedentary, consisting of 23 subjects

Four clusters were identified for females:

Cluster $1=$ Unhealthy habits, consisting of 8 subjects $(11.8 \%)$

Cluster 2=Active overweight, consisting of 34 subjects $(35.3 \%)$

Cluster $3=$ Sedentary, consisting of 18 subjects $(26.5 \%)$

Cluster $4=$ Normal weight, consisting of 18 subjects $(26.5 \%)$

The "Unhealthy habits" cluster was identified in both groups, which was dominant among males; whereas, it was the smallest cluster in females. In both genders the "Unhealthy habits" cluster was characterized by a high prevalence of overweight/obese and abdominal obese subjects, a high prevalence of wine and alcoholic beverages consumers and a high prevalence of inactive subjects; especially in females. In males, the "Unhealthy habits" cluster was characterized by a higher prevalence of neurological patients (60.6\%), although no statistical significance was observed, patients with low education levels $(54.0 \%)$ and older patients (87.8\%). In females, the "Unhealthy habits" cluster registered the lowest prevalence in neurological patients (13.0\%) and the highest prevalence in people with low education levels $(75.0 \%)$.

The "Active" cluster in males was determined by the highest prevalence of physically active patients, a reduced prevalence of both obesity and abdominal obesity, absence of wine and alcohol consumers, a high prevalence of no-smokers; a medium/high education level also prevailed (53.3\%).

The "Active Overweight" cluster, observed in females, was still characterized by the highest prevalence of physically active subjects, absence or very low prevalence of alcohol consumers. Also, it comprised, prevalently of neurological patients $(71.0 \%)$, but with respect to the "Active" cluster it was prevalently formed by overweight or obese subjects.

The "Sedentary" cluster, identified in both males and females, was determined by inactive, overweight or obese subjects, also affected by abdominal obesity and non alcohol consumers. In addition, the "Sedentary" cluster was prevalently formed by older patients, both in males $(89.0 \%)$ and in females $(94.0 \%)$, and by low education levels $(72.0 \%)$ in females.

The "Normal Weight" cluster was observed in females only. It comprised of normal weight females, with adequate sleep duration, prevalently inactive and characterized by reduced prevalence of abdominal obesity and alcohol consumption. 
1.Unhealthy habits $n=33(38.4 \%)$

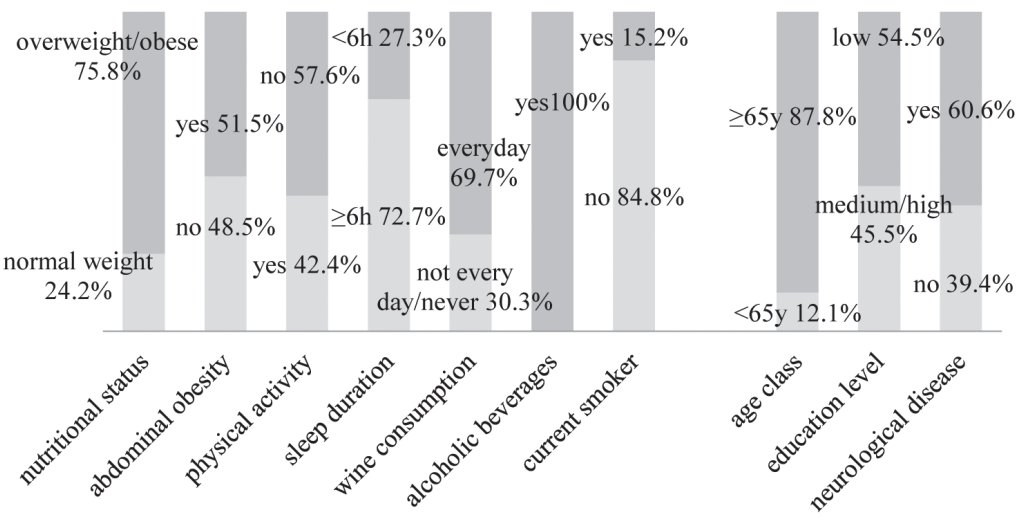

2.Active $n=30(34.9 \%)$

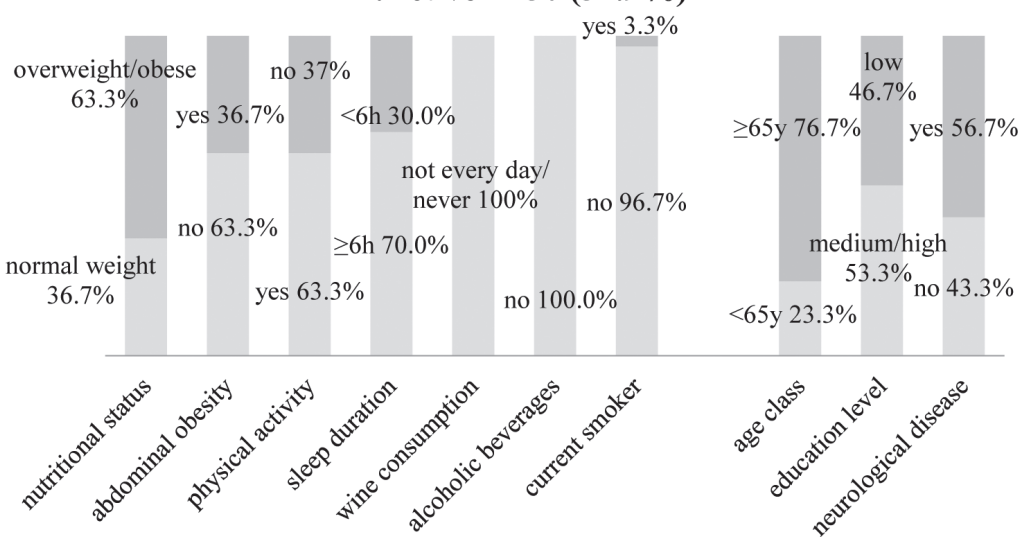

3.Sedentary $n=23(26.7 \%)$

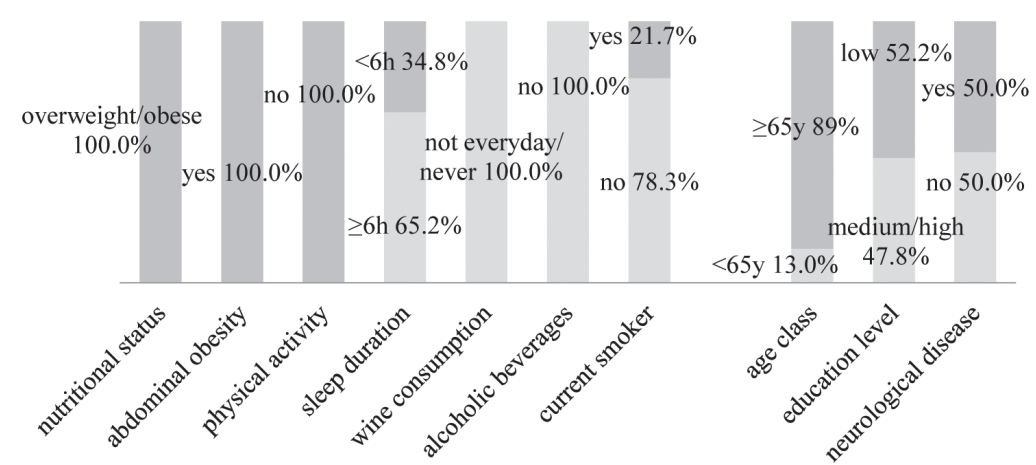

Figure 1 Cluster of lifestyle factors for males 


\section{Unhealthy habits $n=8(11.8 \%)$}

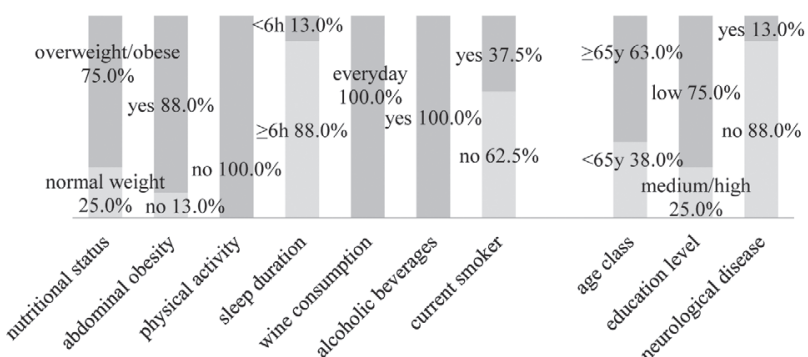

3.Sedentary $n=18$ (26.5)

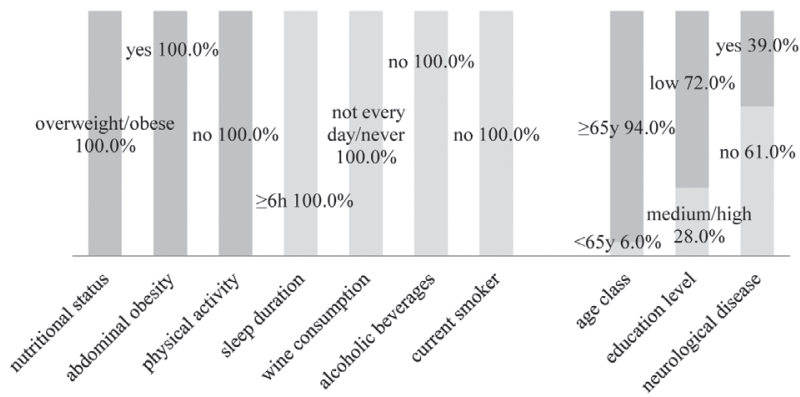

Figure 2 Cluster of lifestyle factors for females

\section{Discussion}

This study was designed to examine characteristics and cluster of lifestyle factors in a small Italian sample of neurological outpatients. The results of this study showed a high prevalence of overweight/obesity and an abdominal obesity that was significantly higher among females.

Obesity and being overweight are considered as high-risk factors for the development of mental health disorders as well as neurodegenerative diseases, such as anxiety, depression, body image disorders, Alzheimer's and Parkinson's disease. ${ }^{9-12}$

Also in our study, it emerged that neurological diseases have a significant prevalence in male subjects (in particular for Parkinson's disease, but also for dementia and stroke), in subjects with a low education level

\section{Active Overweight $n=34(35.3 \%)$}

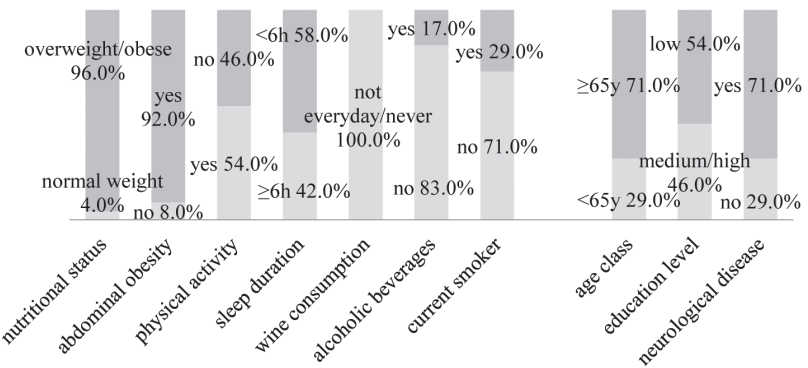

4. Normal weight $n=18(26.5 \%)$

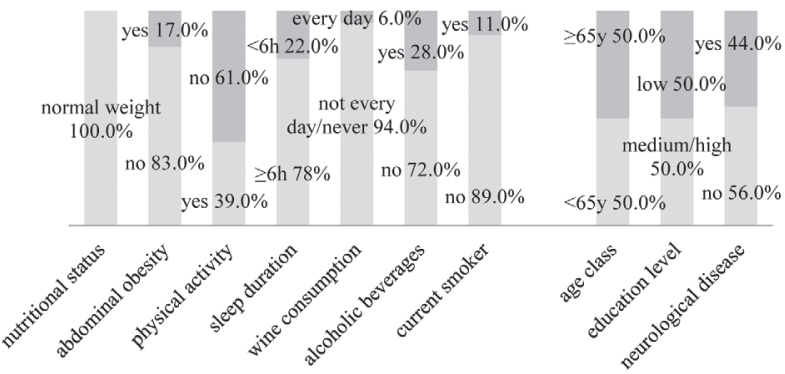

(particularly for dementia), in elderly people (over age 75) and in people getting a significantly lower percentage of appropriate hours of sleep (mainly in Parkinson's disease).

These findings are in accordance with other studies, available in literature, where it was observed that neurological diseases are frequent in older adults and affect $5.0 \%$ to $55.0 \%$ of people aged 55 or older. ${ }^{13,14}$ Additionally, the prevalence of dementia increases with advancing age, affecting nearly $50.0 \%$ of the population over 85 years of age. ${ }^{15}$ Regarding gender, many studies reported it as a significant variable in neurological diseases $^{16-22}$, and in particular it was observed that those of the male gender have a significant risk factor for Parkinson's disease $23-25$; whilst females are more susceptible to Alzheimer's disease. ${ }^{26,27}$ 
Other studies, reporting similar data to our research, showed that a higher education level is associated with a lower risk of dementia, which is thought to be explained by a higher cognitive reserve. ${ }^{28,29}$ In fact, a higher cognitive reserve allows people to endure neurodegenerative diseases, and maintain brain function for a longer extent than people with a low reserve, before the damage manifests clinically as dementia. ${ }^{30-32}$

The results of our study indicated a lower percentage of appropriate hours of sleep, mainly in Parkinson's disease. Sleep disturbance is a common problem in elderly people, as well as in patients affected by mild cognitive impairment and dementia. Some studies reported that shorter as well as longer sleep duration may be important risk factors for future cognitive impairment. ${ }^{33-37}$ One prospective study of the relationship between sleep duration, and risk of dementia also reported that the latter was higher in individuals with long sleep durations, around 8-9 hours and more, with respect to people having normal sleep durations of 6 and 7 hours. It can be thus be assumed that longer sleep duration might be a risk factor for cognitive impairment among older people. ${ }^{38}$

In this study, cluster analysis allowed for the identifying of similar profiles in the sample, depending on lifestyle factors. Three clusters were thus identified for males: (1. Unhealthy habits; 2. Active and 3. Sedentary); and four for females: (1. Unhealthy habits; 2. Active overweight; 3. Sedentary and 4 . Normal weight).

The "Unhealthy habits" cluster, dominant among males, had the least favorable health parameters. It was in fact characterized by a high prevalence of overweight/obese and abdominal obese subjects, a high prevalence of wine and alcoholic beverage consumers, a high prevalence of inactive subjects; especially in females, and by a high prevalence of neurological disease among males. In our research, the proportion of women with unhealthy lifestyle clustering was approximately lower than in men, while those of the male gender were confirmed as an independent risk factor for unhealthy lifestyle clustering.

WHO reported that behaviours; such as, smoking, an unbalanced diet, excessive alcohol consumption and physical inactivity, are the main, modifiable risk factors for the prevention of chronic diseases. These currently account for over $70.0 \%$ of the overall global burden of disease, and which are expected to rise to $80.0 \%$ by the end of $2020 .^{39}$

One more survey evidenced the cluster of unhealthy habits in elderly people. A cross-sectional study, carried out in China, explored the influencing factors of unhealthy lifestyle clustering (for example; unreasonable diets, physical inactivity, smoking, excessive drinking and low health literacy on diabete outcomes) in rural, elderly adults with prediabetes. It found a significant clustering of unhealthy (76.5\%), among the elderly participants, with prediabetes; this clustering was more obvious among the elders aged between 60 and $69 .^{40}$

Our study has, nevertheless, some limitations. First, this survey had a hospital-based design, and patients were seen only one time by the neurologist; as a consequence, follow up data were unavailable. Second, this study, being of a cross-sectional nature, was conducted on a small sample size, which is not representative. In addition, it is possible that other metrics can identify subgroups. This means that the lack of clustering in our analyses does not imply that clusters do not exist. However, if clusters exist they cannot be identified with the variables that were cons.

The strengths of our research lie in its anthropometric variables, which were measured and not selfreported by the subjects. In addition, two indicators of obesity, namely cut-off for $\mathrm{BMI}$ and $\mathrm{WC} / \mathrm{Ht}$, were used. 


\section{Conclusion}

In conclusion; three clusters were identified for males and four for females according to lifestyles. The main, important findings showed a high prevalence of unhealthy lifestyle clustering dominant among male, elderly people with neurological diseases. These data, characterizing the profile of our sample, can be used as a basis for the development of efficient strategies aimed at improving the quality of life. However, due to the limited number of participants in this study these findings require confirmation by further studies, with larger samples.

\section{Acknowledgement}

The authors gratefully thank the people along with their families who participated in this study.

\section{Funding sources}

This research did not receive any specific grant from funding agencies in the public, commercial or not-for-profit sectors.

\section{Conflict of interest}

The authors have no conflicts of interest to declare.

\section{References}

1. Yanguas-Casás N. Sex Differences in Neurodegenerative Diseases. SM J Neurol Disord Stroke 2017;3:1014.

2. Batista P, Pereira A. Quality of life of patients with neurodegenerative diseases. J Neurol Neurosci 2016;7:1-7.

3. Awan S, Shafqat S, Kamran Kamal A, Sonawalla A, Siddiqui S, Siddiqui $F$, et al. Pattern of neurological diseases in adult outpatient neurology clinics in tertiary care hospital. BMC Res Notes 2017;10:545.

4. Lopez A.D, Mathers C, Ezzati M. Global Burden of Disease and Risk Factors. Washington: The World Bank and Oxford University Press; 2006.
5. Birbeck GL, Meyer AC, Ogunniyi A. Nervous system disorders across the life course in resource-limited settings. Nature 2015;527:S167-71.

6. Ministry of Health. Sistema di valutazione e monitoraggio della qualità dell'assistenza e delle performance dei sistemi sanitari [homepage on the Internet]. Rome: Ministry of Health; 2011 [cited 2011 Dec 13]. Aavailable from: www.rssp.salute.gov. it/rssp/paginaParagrafoRssp

7. World Health Organization. Physical status: the use and interpretation of anthropometry. Report of a WHO Expert Committee. Technical Report Series No. 854. Geneva: WHO; 1995.

8. Browning LM, Hsieh SD, Ashwell M. A systematic review of waist-to-height ratio as a screening tool for the prediction of cardiovascular disease and diabetes: 0.5 could be a suitable global boundary value. Nutr Res Rev 2010;23: 247-69.

9. Mazon JN, De-Mello AH, Ferreira GK, Rezin GT. The impact of obesity on neurodegenerative diseases. Life Sci 2017; 182:22-8.

10. McShea S. Obesity: "can the battle be won?". Physician Assist Clin 2017;2:87-106.

11. Procaccini C, Santopaolo M, Faicchia D, Colamatteo A, Formisano L, de Candia P, et al. Matarese G role of metabolism in neurodegenerative disorders. Metabolism 2016;65:137690.

12. Davis C, Mudd J, Hawkins M. Neuroprotective effects of leptin in the context of obesity and metabolic disorders. Neurobiol Dis $2014 ; 72: 61-71$.

13. Hofman A, Murad SD, Van Duijn CM, Franco OH, Goedegebure A, Arfan Ikram M, et al. The Rotterdam Study: 2014 objectives and design update. Eur J Epidemiol 2013; 28:889-926

14. Murray CJ, Vos T, Lozano R, Naghavi M, Flaxman AD, Michaud C, et al. Disability-adjusted life years (DALYs) for 291 diseases and injuries in 21 regions, 1990-2010: a systematic analysis for the Global Burden of Disease Study 2010. Lancet 2012; 380:2197-223.

15. Dorszewska J, Prendecki M, Oczkowska A, Dezor M, Kozubski W. Molecular basis of familial and sporadic Alzheimer's disease. Curr Alzheimer Res 2016;13:952-63.

16. Loke $\mathrm{H}$, Harley $\mathrm{V}$, Lee J. Biological factors underlying sex 
differences in neurological disorders. Int $\mathrm{J}$ Biochem Cell Boil 2015;65:139-50.

17. Young LJ, Pfaff DW. Sex differences in neurological and psychiatric disorders. Front Neuroendocrinol 2014;35:253-4.

18. Ngun TC, Ghahramani N, Sánchez FJ, Bocklandt S, Vilain E. The genetics of sex differences in brain and behavior. Front Neuroendocr 2011;32:227-46.

19. McCarthy MM, Arnold AP, Ball GF, Blaustein JD, De Vries GJ. Sex differences in the brain: the not so inconvenient truth. J Neurosci 2012;32:2241-7.

20. Hanamsagar R, Bilbo SD. Sex differences in neurodevelopmental and neurodegenerative disorders: focus on microglial function and neuroinflammation during development. J Steroid Biochem Mol Boil 2016;160:127-33.

21. Cosgrove KP, Mazure CM, Staley JK. Evolving knowledge of sex differences in brain structure, function, and chemistry. Biol Psychiatry. 2007;62:847-55.

22. Gillies GE, McArthur S. Estrogen actions in the brain and the basis for differential action in men and women: a case for sex-specific medicines. Pharmacol Rev 2010;62:155-98.

23. Gillies GE, Pienaar IS, Vohra S, Qamhawi Z. Sex differences in parkinson's disease. Front Neuroendocr 2014;35:370-84.

24. Haaxma CA, Bloem BR, Borm GF, Oyen WJ, Leenders KL, Eshuis S, et al. Gender differences in parkinson's disease. J Neurol Neurosurg Psychiatry 2007;78:819-24.

25. Van Den Eeden SK, Tanner CM, Bernstein AL, Fross RD, Leimpeter A, Bloch DA, et al. Incidence of parkinson's disease: variation by age, gender, and race/ethnicity. Am J Epidemiol 2003;157:1015-22.

26. Li R, Singh M. Sex differences in cognitive impairment and Alzheimer's disease. Front Neuroendocr 2014;35:385-403.

27. Hebert LE, Weuve J, Scherr PA, Evans DA. Alzheimer disease in the United States (2010-2050) estimated using the 2010 census. Neurology 2013;80:1778-83.

28. Caamano-Isorna F, Corral M, Montes-Martinez A, Takkouche B. Education and dementia: a meta-analytic study. Neuroepidemiology 2006;26:226-32.

29. Meng X, D'Arcy C. Education and dementia in the context of the cognitive reserve hypothesis: a systematic review with meta-analyses and qualitative analyses. PLoS One 2012;7. doi: 10.1371/journal.pone.0038268.
30. Lenehan ME, Summers MJ, Saunders NL, Summers JJ, Vickers JC. Relationship between education and age-related cognitive decline: a review of recent research. Psychogeriatrics 2014;15:154-62.

31. Stern Y. What is cognitive reserve? Theory and research application of the reserve concept. J Int Neuropsychol Soc 2002;8:448-60.

32. Jones RN, Manly J, Glymour MM, Rentz DM, Jefferson AL, Stern Y. Conceptual and measurement challenges in research on cognitive reserve. J Int Neuropsychol Soc 2011;17:593601.

33. Benito-León J, Bermejo-Pareja F, Vega S, Louis ED. Total daily sleep duration and the risk of dementia: a prospective population-based study. Eur J Neurol 2009;16:990-7.

34. Oosterman JM, van Someren EJ, Vogels RL, Van Harten B, Scherder EJ. Fragmentation of the rest-activity rhythm correlates with age-related cognitive deficits. J Sleep Res 2009;18:129-35.

35. Benito-León J, Louis ED, Villarejo-Galende A, Romero JP, Bermejo Pareja F. Long sleep duration in elders without dementia increases risk of dementia mortality (NEDICES). Neurology 2014;83:1530-7.

36. Da Silva RA. Sleep disturbances and mild cognitive impairment: a review. Sleep Sci 2015;8:36-41.

37. Spira AP, Stone KL, Redline S, Ensrud KE, Ancoli-Israel S, Cauley JA, et al. Actigraphic sleep duration and fragmentation in older women: associations with performance across cognitive domains. Sleep 2017;40. doi: 10.1093/sleep/ zsx073.

38. Kimura N, Aso Y, Yabuuchi K, Ishibashi M, Hori D, Sasaki Y, et al. Modifiable lifestyle factors and cognitive function in older people: a cross-sectional observational study. Front Neurol 2019;10:1-12.

39. World Health Organization. Library cataloging-in-publication data: innovative care for chronic conditions: building blocks for action. Geneva: WHO; 2002.

40. Wang X, Gao H, Xu H. Cluster analysis of unhealthy lifestyles among elderly adults with prediabetes: a crosssectional study in rural china. Diabetes Ther 2019;10:193548. 